\title{
ND: Yag Laser Excision of Lower Lip Mucocelesin Pediatric Dentistry: 12-Year Follow-Up Case Report
}

\author{
Almeida ER ${ }^{1 *}$, Baeder FM², Duarte DA ${ }^{2}$, Pelino JEP ${ }^{3}$ \\ ${ }^{1}$ School of Dentistry, Cruzeiro do Sul University, Brazil \\ ${ }^{2}$ School of Dentistry, Paulista Dental Association, Brazil \\ ${ }^{3}$ School of Dentistry, Fellow at Paulista Dental Association, Brazil
}

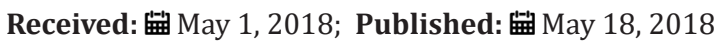

*Corresponding author: Almeida ER, School of Dentistry, Cruzeiro do Sul University, Brazil

\begin{abstract}
Mucoceles is the most common benign minor salivary gland lesion commonly affecting children and adolescents, being more prevalent on lower labial mucosa with periodic rupture history and local trauma. A complete excision is recommended for mucoceles, including associated salivary gland tissue and marginal glands. Conventional surgical intervention as well as laser excision is indicated. This case report describes lower lip mucoceles excision with an Nd: YAG laser in a 6-year-old girl, with no recurrence after 12 years. When properly used, Nd: YAG laser can play a beneficial role to both clinicians and patients in achieving high quality results, as it provides good hemostasis, reduced postoperative swelling, bacterial reduction at the surgical site, lesser need for suturing, faster healing, and less postoperative pain. The success of this procedure was reflected due to a lack of recurrent lesion with a comprehensive follow up period of 12 years.
\end{abstract}

\section{Introduction}

Mucoceles is referred to a mucus extravasations or retention phenomenon of mucus, depending on the presence of epithelial lining [1] with a higher prevalence on the lower labial mucosa [2]. Treatment options are surgical interventions, cryosurgery, marsupialization, and micro-marsupialization [3,4]. High intensity lasers are also indicated, as a suitable procedure for children [57], as it provides good hemostasis, reduced postoperative swelling, bacterial reduction at the surgical site, lesser need for suturing, faster healing, and less postoperative pain [8]. Regardless of the technique, recurrency is one important factor to consider. So, the aim of this report is to describe a mucoceles excision with Nd:YAG laser on the lower lip of an infant patient, with a 12-year follow-up.

\section{Case Report}

A six-year-old girl was referred to the Pediatric Dentistry Clinic, Cruzeiro do Sul University (Sao Paulo, Brazil) with the presence of a mucoceles in the lower lip, with the size of $0.6 \times 0.6 \mathrm{~cm}$ in size and around $0.6 \mathrm{~cm}$ in width. Her mother reported that a same lesion had already been removed 6 months ago by conventional surgery but it had recurred. The patient was healthy and no other symptoms were reported. Selected treatment consisted on removing the whole lesion by using a high power Nd:YAG laser(1,064nm). Preoperative laboratorial exams as blood count coagulogram and glicemy were requested to investigate the systemic conditions. The use of antibiotic preoperative medication was not indicated. The lesion was further sent for histopathological analysis which confirmed to be a mucoceles. Intra-oral antisepsis was performed with gluconate chlorhexidine at $0.12 \%$ mouthwash (Perioxidim ${ }^{\circledR}$ Glaxo Welcome S.A) with $15 \mathrm{ml}$ for 30 seconds and extra-oral antisepsis with gluconate chlorhexidine at 2\% (Methiolate $\AA$ Dm Pharmaceutical Industry Ltd). After local anesthesia using mepivacaine with epinephrine 1:100.000, excision process of the lesion was started, following lesion outline with a high power Nd:YAG laser, in a contact mode with a fiber optic delivery system with a spot size of 320 microns in diameter. During this procedure, a quartz fiber was also used in close contact with the tissue (at a $45^{\circ}$ angle) to avoid excessive heat transmission to deep tissues, and consequently, tissue injuries. The Nd:YAG laser parameters used throughout the procedure were: 1,064nm; $2.0-3.0 \mathrm{~W} ; 15-20 \mathrm{~Hz} ; 133-$ $150 \mathrm{~mJ}$ at $166.25-187.50 \mathrm{~J} / \mathrm{cm} 2$. Right after the total lesion excision, 
a low-intensity laser (GaAsAI - Gallium Arsenide and Aluminum MMOPTICS Brazil; $670 \mathrm{~nm}, 50 \mathrm{~mW}$ at $4.0 \mathrm{~J} / \mathrm{cm} 2$ ) was used, aiming to help achieve a fast wound healing tissues process, with less postoperative pain and inflammation [9]. The patient experienced no discomfort during the procedure except for a tingling sensation at some regions. There was no bleeding during the procedure. Following vaporization, the power setting was reduced and the laser was operated in a continuous and defocused mode to create a protective chelated layer of denatured proteins over the lesion which helped prevent oral fluids and any irritant material from getting in contact with the surgical site besides assisting on the reduction of postoperative discomfort. The entire procedure duration was of approximately 4 minutes. As part of the postoperative care, paracetamol (500 $\mathrm{mg}$ ) was prescribed every 4 hours, for 3 days, in the case of pain. The period of 24 hours showed recovery of the lesion, with scaring tissue. Following this, a low-intensity laser was applied with the same parameters of the first application, and this protocol was repeated after 48 and 72 hours. No pain or discomfort was reported. After 30 days, clinical evolution was analyzed without signs of inflammation, infection or scaring, and re-establishment of the anatomy was observed, as well as aesthetics and recovery of the mouth function, without traumatism of the surgical area. A 12-year follow-up showed no recurrent lesions (Figures 1-4).
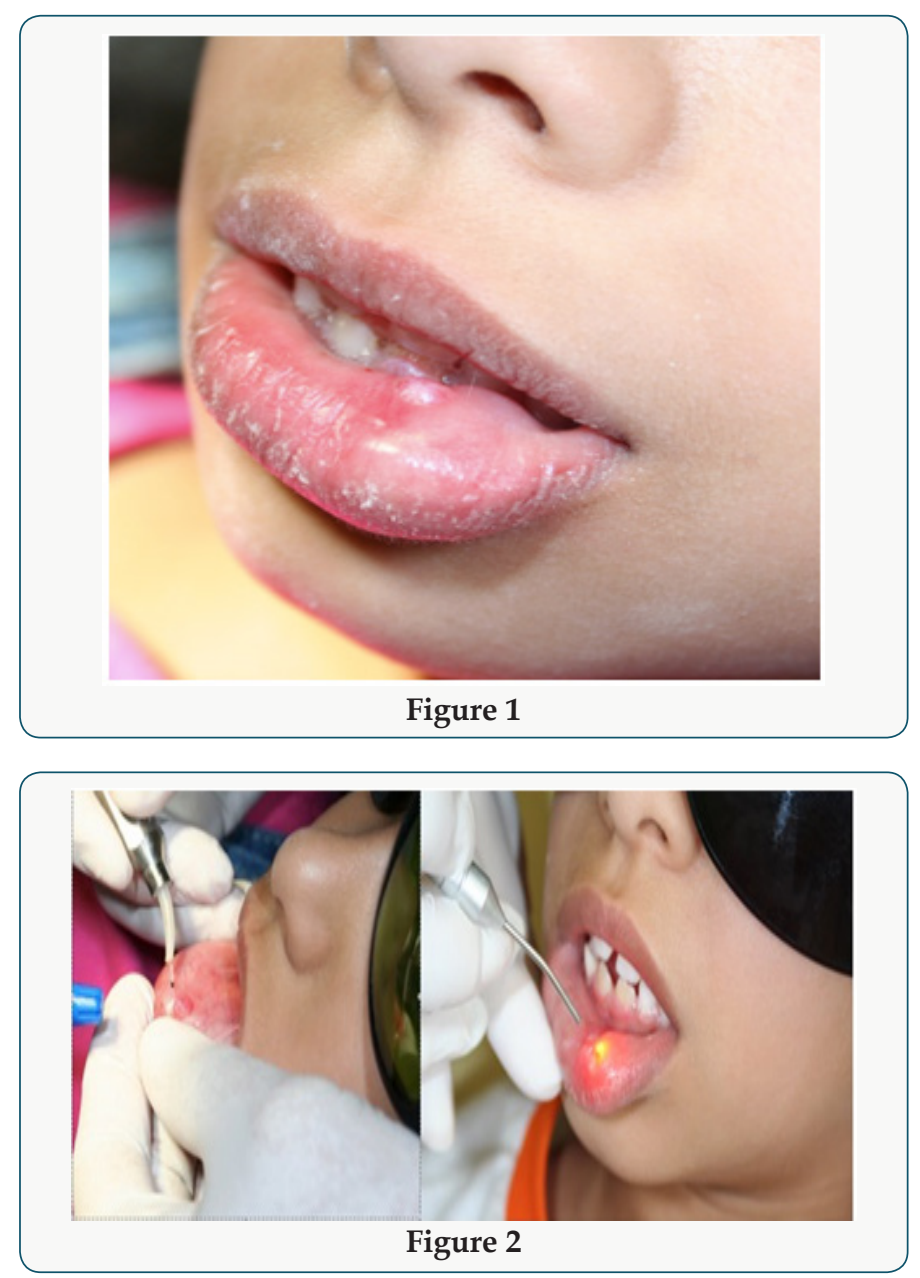
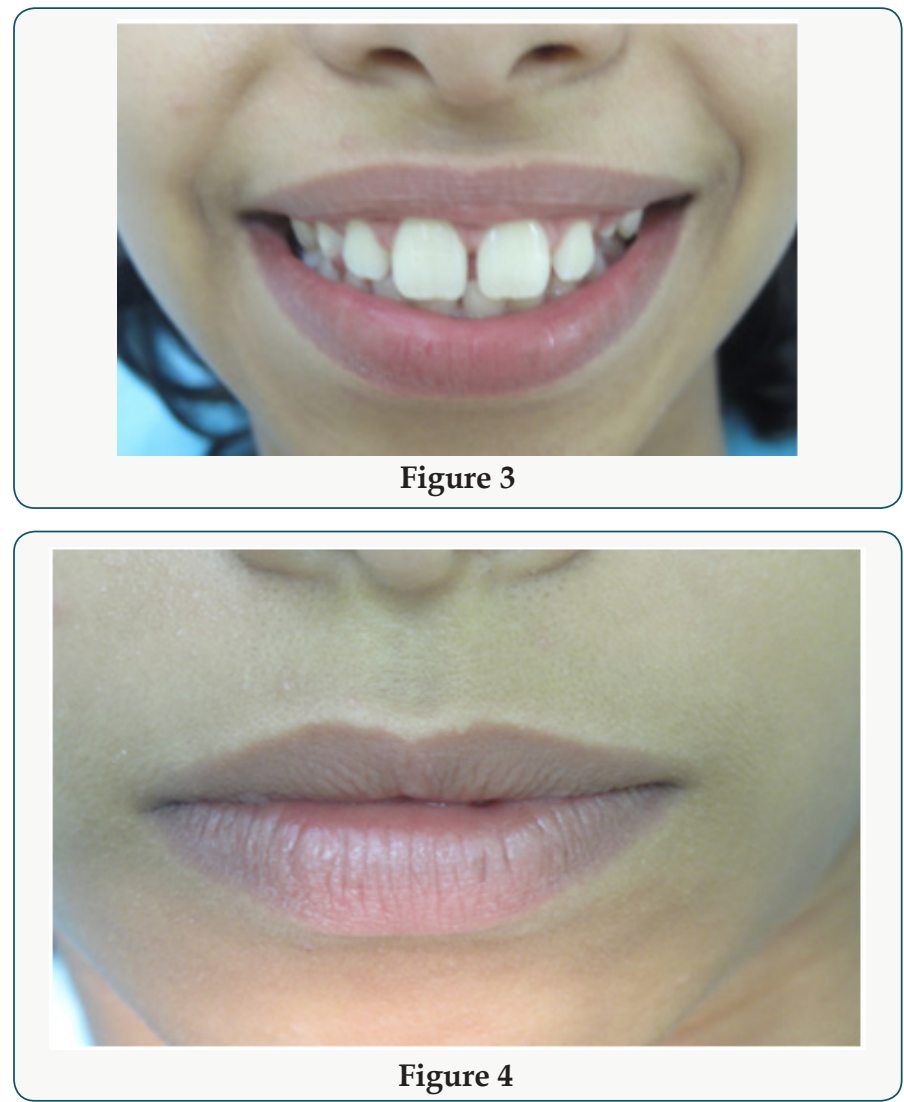

\section{Discussion}

Lesion location and patient's age can bring difficulties for surgical treatment, regarding the need of child cooperation during the surgery and at the postoperative period. Moreover, lasers provide satisfactory results with low recurrence rates and are well tolerated by young patients [2]. Various types of lasers, such as CO2 [10, 11], Erbium [7] and diode lasers [8,12] are used for vaporization and complete excision of mucoceles; Argon [13] and Nd:YAG lasers [14] are used for complete lesion excision; Diode (980nm) and CO2 (10.600 nm) lasers can also be used for soft tissue surgery. On the other hand, several studies have indicated other wavelengths such as a high power pulsed Nd: YAG laser $(1,064 \mathrm{~nm})$ or high-power continuous diode laser $(810 \mathrm{~nm})$. High-intensity lasers have been efficiently recommended due to its prompt hemostasis and no need to suture, with reduced surgical time and wound infection [15]. Comparing to conventional surgeries, oral surgery when properly performed with high-power surgical lasers, such as the Nd:YAG laser, promotes a homogenous tissue excision and an excellent hemostasis, which enables a better surgical site view and thus promotes a faster, safer and more precise surgery. Due to their precise tissue excision capability, high-power lasers reduce the possibility of bacteremia, which makes the post-surgery period more comfortable and safer, representing a crucial point for Pediatric Dentistry. Our clinical findings included sufficient hemostasis and precise excision margin removal for the surgical procedure. The main advantages claimed for Nd:YAG laser surgery are the reduction of post-operative pain and infection; minimal 
contraction and scarring; reduced post-operative inflammation; no sutures due to the hemostasis and denatured protein forms as a natural wound dressing, as observed in this procedure for young patients. As a positive surgical outcome the present study highlights the optimal use of the Nd:YAG laser, as an excellent and precise tool for the surgical excision of mucoceles in children, with no recurent lesions after 12 years. Considering these beneficial effects, the Nd:YAG laser represents a great potential in Pediatric Dentistry, as a very suitable tool for mucoceles removal in children.

\section{References}

1. Nico MMS, Park JH, Lourenço SV (2008) Mucoceles in pediatric patients: Analysis of 36 children. Pediatr Dermatol 25(3): 308-311.

2. Huang IY, Chen CM, Kao YH, Worthington P (2007) Treatment of mucoceles of the lower lip with carbon dioxide laser. J Oral Maxillofac Surg 65(5): 855-888.

3. R, Melman G, Karic V (2016) Lasers in Pediatric Dentistry. S Afr Dent ] 71(9): 421.

4. Khandelwal S, Patil S (2012) Oral mucoceles - review of the literature. Minerva Stomatol 61(3): 91-99.

5. Piazzetta CM, Torres Pereira C, Amenábar JM (2012) Micromarzupialization as an alternative treatment for mucoceles in pediatric dentistry. Int J Paediatr Dent 22(5): 318-323.

6. Baggett FJ, Mackie IC, Blinkhorn AS (1999) The clinical use of the $\mathrm{Nd}$ :YAG laser in pediatric dentistry for the removal of oral soft tissue. British Dent J 187(10): 528-30.
7. Boj JR, Poirier C, Espasa E, Hernandez M, Espanya A (2009) Lower lip mucocele treated with an erbium laser. Pediatr Dent 31(3): 249-252.

8. Sukhtankar LV, Mahajan B, Agarwal P (2013) Treatment of lower lip mucoceles with diode laser - a novel approach. Ann Dent Res 2(Supl 1):102-108.

9. Bowman JM, Levy BA, Grubb RV (1988) Gingival overgrowth induced by diltiazem. Oral Surg Oral Med Oral Pathol 65(2): 183-185.

10. Coleton S (2004) Lasers in surgical periodontics and oral medicine. Dent Clin North Am 48(4): 937-962.

11. Yagüe García J, España Tost AJ, Berini Aytés L, Gay Escoda C (2009) Treatment of oral mucocele-scalpel versus $\mathrm{CO} 2$ laser. Med Oral Patol Oral Cir Bucal 14(9): 469-474.

12. Pedron IG, Galletta VC, Azevedo HL, Corrêa L (2010) Treatment of Mucocele of the Lower Lip with Diode Laser in Pediatric Patients: Presentation of 2 Clinical Cases. Pediatr Dent 32(7): 539-541.

13. Neumann RA, Knobler RM (1990) Treatment of oral mucous cysts with an argon laser. Arch Dermatol 126(6): 829-830.

14. Jinbu Y, Tsukinoki K, Kusama M, Watanabe Y (2003) Recurrent multiple superficial mucocele on the palate: Histopathology and laser vaporization. Oral Surg Oral Med Oral Pathol Oral RadiolEndod 95(2): 193-197.

15. Gregnanin VI (2010) Treatment of Mucocele of the Lower Lip With Diode Laser in Pediatric Patients: Presentation of 2 Clinical Cases. Pediatr Dent 32(7): 539-541.

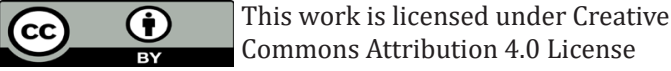

To Submit Your Article Click Here:

Submit Article

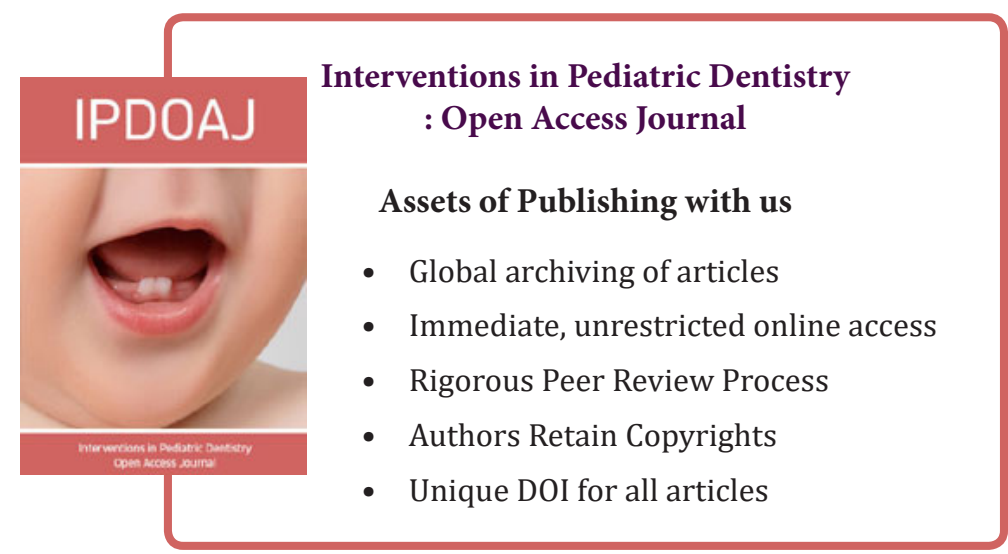

